\title{
openheart Treatment choices in elderly patients with ST: elevation myocardial infarction - insights from the Vital Heart Response registry
}

Olga Toleva, ${ }^{1}$ Quazi Ibrahim, ${ }^{1}$ Neil Brass, ${ }^{2}$ Sunil Sookram, ${ }^{1}$ Robert Welsh ${ }^{1,3}$

To cite: Toleva O, Ibrahim Q, Brass N, et al. Treatment choices in elderly patients with ST: elevation myocardial infarction-insights from the Vital Heart Response registry. Open Heart 2015;2:e000235. doi:10.1136/openhrt-2014000235

Received 27 December 2014 Revised 12 May 2015 Accepted 3 June 2015
CrossMark

\section{${ }^{1}$ University of Alberta, Edmonton, Alberta, Canada ${ }^{2}$ Royal Alexandra Hospital and CK Hui Heart Centre, Edmonton, Alberta, Canada ${ }^{3}$ Mazankowski Alberta Heart Institute, Edmonton, Alberta, Canada}

Correspondence to Dr Robert Welsh; Robert.Welsh@ albertahealthservices.ca

\section{ABSTRACT}

Background: Management of elderly patients with ST elevation myocardial infarction (STEMI) is challenging and they are under-represented in trials. Accordingly, we analysed reperfusion strategies and their effectiveness in patients with STEMI $\geq 75$ years compared to $<75$ years within a comprehensive inclusive registry.

Methods: Consecutive patients with STEMI admitted to hospital and tracked within a regional registry (2006-2011) were analysed comparing reperfusion strategy (primary percutaneous coronary intervention (PPCl), fibrinolysis and no reperfusion) between patients $\geq 75$ vs $<75$ years old as well as across the reperfusion strategies in those $\geq 75$ years.

Results: There were 3588 patients with STEMI with $646(18 \%) \geq 75$ years old. Elderly patients were more likely female $(46.9 \%$ vs $18.4 \%)$ and had more prior: angina (28.2\% vs $17.2 \%)$, myocardial infarction (Ml; $22.8 \%$ vs $13.9 \%$ ), hypertension ( $67.6 \%$ vs $44.2 \%$ ), heart failure $(2.3 \%$ vs $0.3 \%)$ and atrial fibrillation $(2.2 \%$ vs $0.5 \%)$ (all $p<0.001$ ). The reperfusion strategy for patients $\geq 75$ vs $<75$ : PPCI $45.3 \%$ vs $41.2 \%$, fibrinolysis $24.8 \%$ vs $45.7 \%$, and no reperfusion $29.9 \%$ vs $13.1 \%(p<0.001)$. Time from symptoms to first medical contact (median, 93 vs 78 min $p=0.008$ ) and $\mathrm{PPCl}$ (median, 166 vs $136 \mathrm{~min}(\mathrm{p}<0.001)$ were longer for $\geq 75$ years. In those $\geq 75$ years outcomes by reperfusion (PPCl, fibrinolysis and none) were: inhospital death $13.3 \%, 9.4 \%$ and $19.7 \%(p=0.018)$, and composite of death, recurrent-MI, cardiogenic shock and congestive heart failure $28 \%, 20 \%$ and $33.2 \%$ ( $p=0.022)$.

Conclusions: Elderly patients have more comorbidities, worst in-hospital clinical outcomes and are less likely to receive reperfusion. Acknowledging physician selection of the reperfusion strategy; outcomes appear favourable in the elderly receiving fibrinolysis.

\section{BACKGROUND}

The demographic shift with increasingly aging population, results in higher incidence of elderly patients presenting with acute coronary syndromes (ACS). Significant

\section{KEY MESSAGES}

What is already known about this subject?

- Timely reperfusion therapy improves outcomes in patients with ST elevation myocardial infarction (STEMI). Primary percutaneous coronary intervention $(\mathrm{PCl})$ is the dominant reperfusion strategy if it can be delivered rapidly by an experienced interventional cardiologist and team. Substantial intellectual and financial equity has been invested to develop regional STEMI networks focused on optimising patient outcomes.

What does this study add?

- This study adds information regarding reperfusion strategies and outcomes elderly patients with STEMI from a 'real world' perspective. To date there is limited randomised controlled trial data specific to elderly patients with STEMI and limited 'real world' data address this issue.

How might this impact on clinical practice?

- Our study demonstrates that one of three of elderly patients receive no reperfusion and that although primary $\mathrm{PCl}$ is the preferred reperfusion strategy that outcomes with fibrinolysis in this population are excellent. This data provides impetus to optimise reperfusion in this very high-risk population and identifies that the selective use of fibrinolysis can achieve excellent outcomes.

age-associated heterogeneity in baseline characteristics has been described to account for some of the differences in mortality from acute myocardial infarction (MI) in subgroups of elderly patients. ${ }^{1}$ There is a gap between the evidence from ST elevation myocardial infarction (STEMI) randomised controlled trials (RCT's) and real life due to under-representation of elderly patients in these trials. ${ }^{2}$ The proportion of patients eligible for reperfusion strategy decreases with advancing age and elderly patients are still less likely to receive reperfusion even if 
eligible. ${ }^{3}$ Furthermore data suggests that morbidity and mortality from STEMI is higher in elderly compared to younger patients. ${ }^{4}$ With the existing reperfusion therapies there is still uncertainty about their use in the elderly despite evidence for mortality benefit for both fibrinolysis and primary percutaneous coronary intervention (PPCI) from RCTs and registries. ${ }^{5-7}$ Accordingly, we compared the baseline characteristics, reperfusion strategies and outcomes between elderly ( $\geq 75$ years of age) and younger patients within an inclusive 'real world registry'. Additionally, we assessed the outcomes according to the reperfusion strategy used specific to the elderly group.

\section{METHODS}

The study is a retrospective cohort analysis of the Vital Heart Response (VHR) registry which includes consecutive patients with STEMI in the period 2006 until 2011. Medical charts of all patients with an International Classification of Diseases (Ninth and 10th Revision) code for MI were reviewed to identify all patients with STEMI. Detailed data on patient demographic characteristics, mode of presentation, treatment time intervals, reperfusion therapy, in-hospital management and in-hospital events were abstracted by trained data analysts using standardised operation manuals for consistency and validity at the Epidemiology Coordinating and Research Centre at the University of Alberta (EPICORE). First medical contact (FMC) was defined using strict definition of the time of first healthcare practitioner contact documented on the patients' chart. This included arrival of the prehospital paramedical personnel at the patient's side even if prehospital diagnosis of STEMI was not obtained. For self-presenting patients, FMC was defined as the first recorded triage or registration time.

VHR is a regional reperfusion programme in Central and Northern Alberta. There are five centres in metropolitan Edmonton with two primary PCI centres. The estimated catchment area for the population is about $440000 \mathrm{~km}^{2}$ serving 1.8 million inhabitants and approximately $44 \%$ of the study population lives in a nonmetropolitan region. The VHR system is activated by Emergency Medical Services from the ambulance or emergency physicians from the emergency departments, when the clinical history and 12-lead ECG are compatible with a STEMI. For prehospital patients, the 12-lead ECG is electronically transmitted to the VHR physician who confirms the diagnosis and reviews the clinical history with the on-site practitioner and then decides on one of the two reperfusion strategies in the protocol (PPCI or fibrinolysis) depending on patient's characteristics and the estimated temporal factors. For in-hospital patients with STEMI, on-site clinicians review the patient's characteristics and investigations and determine the reperfusion strategy with the potential to activate the VHR process of care described for prehospital patients. Practising clinicians typically follow the American College of Cardiology and American Heart Association
STEMI guidelines. The VHR registry includes all patients with STEMI that survive to hospital regardless of activation of the VHR protocol described above.

\section{Reperfusion therapy}

Reperfusion strategy is defined as the therapy within $24 \mathrm{~h}$ of presentation (only one of the following may be recorded for any patient): No reperfusion therapy-when the patient does not receive any primary reperfusion (no PPCI and no Fibrinolytic); Fibrinolytic-when the patient receives fibrinolytic agent as a reperfusion strategy; PPCI - when the patient receives cardiac catheterisation with the intent to conduct PPCI including patients who were sent for angiogram but were unable to receive stent or balloon inflation.

All patients receive a loading dose of acetylsalicylic acid (>160 mg). For the Fibrinolytic strategy: weight-adjusted tenecteplase (TNK), clopidogrel $300 \mathrm{mg}$ loading dose ( $75 \mathrm{mg}$ daily), and enoxaparin (30 $\mathrm{mg}$ intravenous and $1 \mathrm{mg} / \mathrm{kg}$ subcutaneous) are given. For patients $\geq 75$ years the loading dose of clopidogrel and the intravenous enoxaparin are omitted, and the subcutaneous dose of enoxaparin is reduced to $0.75 \mathrm{mg} / \mathrm{kg}$. For patients assigned to primary PCI clopidogrel $600 \mathrm{mg}$ is given. Prehospital diagnosed and treated patients receive intravenous $(30 \mathrm{mg})$ and subcutaneous $(1 \mathrm{mg} / \mathrm{kg})$ enoxaparin, and patients diagnosed in hospital typically receive unfractionated heparin (70 U/kg intravenous).

\section{Study cohorts, definitions and statistical analysis}

Participants in this study were divided into two groups according to age: elderly group ( $\geq 75$ years old) and younger group $(<75$ years old). For the current analysis the Primary outcome was defined as the composite of in-hospital death, recurrent MI (Re-MI), cardiogenic shock and congestive heart failure (CHF). Secondary out comes (with definitions) included in-hospital: death of any cause, Re-MI (recurrent symptoms, ST elevation and CK elevation); Cardiogenic shock (evidence of systolic blood pressure $<90 \mathrm{~mm} \mathrm{Hg}$ for at least $30 \mathrm{~min}$ in the presence of normal heart rate with signs of end organ hypoperfusion (cool extremities, low urine output, mental confusion), with inotropic support for more than $30 \mathrm{~min}$, mechanical support with intra-aortic balloon pump (shock postcoronary artery bypass grafting (CABG) was not recorded); and CHF (newly diagnosed heart failure and at least one of the following conditions requiring treatment with diuretics: pulmonary oedema/congestion on chest X-ray, crackles greater than $1 / 3$ of the lung fields (Killip class $>2$ ) and dyspnoea with oxygen saturation less than $90 \%$ in the absence of known lung disease). Safety outcomes (with definitions) included: cerebrovascular event (CVA) with haemorrhagic stroke (CT scanning, MRI or autopsy); CVA with ischaemic stroke (lateralising neurological complications after the time of admission and prior to discharge). Major bleeding with or without blood transfusion: bleeding that causes hemodynamic compromise 
requiring blood or fluid replacement, inotropic support, ventricular assist device, intra-aortic balloon pump, surgical intervention or cardiopulmonary resuscitation to maintain a sufficient cardiac output or a decrease in the haemoglobin by $>30 \mathrm{~g} / \mathrm{L}$ with hypotension or signs of shock. Minor bleeding: not requiring blood transfusion and not leading to a hemodynamic compromise requiring other intervention or support. Bleeding post-CABG is recorded separately.

Demographic characteristics, health risk factors, treatment choices and in-hospital clinical outcomes were compared between age $\geq 75$ years and age $<75$ years patients with STEMI. Means (SDs) or medians (IQRs) were reported for continuous variables. Categorical variables were presented as counts (percentages). For comparison of continuous variables between elderly and younger patients, $t$ test or Mann-Whitney $U$ test was used. The $\chi^{2}$ or Fisher's exact test was used for categorical variables.

We examined the associations of treatment choices, demographic characteristics, and health risk factors with the composite outcome in the overall study population and in particular, elderly patient's $\geq 75$ years. Exploratory data analyses were performed to detect possible association of these variables with the outcome. Multivariable logistic regression analyses were performed to see the association of clinically relevant variables with the outcome.

A multivariable regression model of the outcome was fitted with the variables that were found significant $(p<0.20)$ at the univariable analyses and were clinically important. The variables that were significant at $\mathrm{p}<0.05$ are kept in the model along with clinically relevant variables. Analyses were performed using statistical packages STATA V.12 and IBM SPSS Statistics V.21.

\section{RESULTS}

\section{For patients $\geq 75$ years old compared to $<75$ years old}

In this registry there were 646 who were $\geq 75$ years old and 2942 patients who were $<75$ years old. Elderly patients were more often female and had more comorbidities including: prior angina, prior MI, prior heart failure and hypertension (table 1). More elderly had a new left bundle branch block as the presenting ECG $(4.4 \%$ vs $1.5 \%, \mathrm{p}<0.001)$; whereas lateral MI was seen in less proportion of the elderly compared to younger patients $(23.3 \%$ vs $29.0 \%, p=0.005)$. No significant differences were identified in the proportions of elderly versus young with presentation of anterior MI ( $45.4 \%$ vs $43.3 \%, \mathrm{p}=0.36)$; inferior MI $(53 \%$ vs $55.2 \%$, $\mathrm{p}=0.313)$, posterior MI $(6.9 \%$ vs $8.7 \%, \mathrm{p}=0.152)$ respectively. There was no significant difference in the presenting heart rate between the two groups, but more elderly patients had higher Killip class $>1$ compared to younger patients (table 1 ). The majority of elderly patients arrived by ambulance $62 \%$ vs $39 \% \quad(p<0.001)$. Time from symptom onset to FMC and time from FMC to initiation of reperfusion were longer in the elderly (table 1 ). The length of hospital stay was longer in the elderly with a median duration of 6 days vs 4 days $(p<0.001)$.

The implementation of various reperfusion strategies by 10-year age increments starting at $<50$ years and ending at $>80$ years showed that with increasing age there is increased use of no reperfusion therapy, decreased use of fibrinolysis and similar usage of PPCI (figure 1). PPCI was performed in $45 \%$ vs $41 \%$ ( $p=0.054$ ), fibrinolysis in $25 \%$ vs $46 \%(<0.001)$ and no reperfusion therapy in $30 \%$ vs $13 \%(\mathrm{p}<0.001)$ in those $\geq 75$ years old and $<75$ years old respectively. Intravenous glycoprotein IIb/IIIa receptor inhibitors during index hospitalisation were utilised in $26.3 \%$ and $43.8 \%$ ( $p<0.001)$, respectively. In patients $\geq 75$ years they were utilised during index hospitalisation in $43.8 \%$ receiving PPCI and $15.2 \%$ receiving fibrinolysis whereas in those $<75$ years they were utilised in $71.7 \%$ receiving PPCI and $29.2 \%$ receiving fibrinolysis.

The in-hospital clinical events by age are shown in table 2. Elderly patients had higher in-hospital events including: the composite of death, re-MI, cardiogenic shock and CHF occurred in $27.6 \%$ vs $13.5 \%$ ( $p<0.001)$ and all individual secondary outcomes (table 2). The safety outcome showed higher rates of ischaemic stroke and major bleeding requiring transfusion in the elderly, and no difference in haemorrhagic stroke between the two groups (table 2).

When looking at the outcomes by age and reperfusion strategy following became evident: In the patients $\geq 75$ years old the composite outcome occurred in $33.2 \%$ of the no-reperfusion therapy group $(n=193), 28 \%$ of the PPCI group $(n=293)$ and $20 \%$ of the fibrinolytic group $(n=160) \quad(p=0.022)$. Death rates were $19.7 \%$ of the no reperfusion therapy group, $13.3 \%$ of the PPCI group and $9.4 \%$ of the fibrinolytic group $(p=0.018)$. In comparison in the $<75$ years old group composite outcome occurred in $17.4 \%$ of the no reperfusion therapy group $(n=386), 15.8 \%$ of the PPCI group $(n=1213)$ and $10.3 \%$ of the fibrinolytic group $(n=1343) \quad(p<0.001)$. Death rates were $6.5 \%$ of the no reperfusion therapy group, $4.6 \%$ of the PPCI group and $2.2 \%$ of the fibrinolytic group $(\mathrm{p}<0.001)$.

Across all three strategies in the whole cohort there was significant utilisation of invasive procedures and revascularisation during the index hospitalisation. In those receiving no reperfusion therapy 417 (72\%) underwent angiography, 254 (44\%) had non-urgent PCI and $35(6 \%)$ had CABG. In those receiving fibrinolysis $348(23.1 \%)$ had rescue PCI, $287(19.1 \%)$ had urgent PCI, $531(35.3 \%)$ had non-urgent PCI and $74(4.9 \%)$ had CABG. In those undergoing primary PCI an additional $111(7.4 \%)$ had non-urgent PCI and 29 (1.9\%) had CABG.

After adjustment for multiple variables that were described in the methods section using logistic regression analysis we were able to identify the following significant predictors of the composite outcome for the 
Table 1 Selected baseline and clinical characteristics at presentation, mode of transport and temporal factors for patients with STEMI in Alberta, 2006-2011

\begin{tabular}{|c|c|c|c|}
\hline & Age $\geq 75$ years $(N=646)$ & Age $<75$ years $(\mathrm{N}=2942)$ & p Value \\
\hline Age (year), mean (SD) & $82.2(5.1)$ & $57.2(9.7)$ & $<0.001$ \\
\hline Female & 303 (46.9) & $540(18.4)$ & $<0.001$ \\
\hline Prior angina & $182(28.2)$ & $506(17.2)$ & $<0.001$ \\
\hline Previous Ml & $147(22.8)$ & 410 (13.9) & $<0.001$ \\
\hline Coronary revascularisation & $80(12.4)$ & 335 (11.4) & 0.473 \\
\hline Hypercholesterolemia & $264(40.9)$ & $1269(43.1)$ & 0.292 \\
\hline Hypertension & $437(67.6)$ & $1300(44.2)$ & $<0.001$ \\
\hline Diabetes & $126(19.5)$ & $519(17.6)$ & 0.264 \\
\hline Prior heart failure & $15(2.3)$ & $9(0.3)$ & $<0.001$ \\
\hline Atrial fibrillation & $14(2.2)$ & $16(0.5)$ & $<0.001$ \\
\hline Smoking & $301(46.6)$ & $2233(75.9)$ & $<0.001$ \\
\hline \multicolumn{4}{|l|}{ Infarct location on first diagnostic ECG } \\
\hline Anterior & $269(45.4)$ & $1137(43.3)$ & 0.360 \\
\hline Inferior & $314(53.0)$ & $1451(55.2)$ & 0.313 \\
\hline Lateral & $138(23.3)$ & $760(29.0)$ & 0.005 \\
\hline New LBBB & $26(4.4)$ & $39(1.5)$ & $<0.001$ \\
\hline Posterior & $41(6.9)$ & $229(8.7)$ & 0.152 \\
\hline Heart rate (first recorded) bpm & $77(63-94)$ & $76(63-90)$ & 0.109 \\
\hline Killip class & & & $<0.001$ \\
\hline 1 & $246(77.1)$ & $1198(89.1)$ & \\
\hline ॥I & $42(13.2)$ & $76(5.7)$ & \\
\hline III & $4(1.3)$ & $2(0.1)$ & \\
\hline IV & $27(8.5)$ & $68(5.1)$ & \\
\hline Arrival by ambulance to first hospital & $403(62.4)$ & $1139(38.8)$ & $<0.001$ \\
\hline Time from symptom onset to FMC (min) & $93(40-240) n=499$ & $78(36-182) \mathrm{N}=2546$ & 0.008 \\
\hline Time from FMC to Fibrinolytic ( $\mathrm{min})$ & $57(39-92) n=150$ & $51(33-80) n=1289$ & 0.028 \\
\hline Time from FMC to primary $\mathrm{PCl}(\mathrm{min})$ & $166(106-272) n=214$ & $136(102-208) n=991$ & $<0.001$ \\
\hline Length of stay in hospital (in days) & $6(4-11) n=626$ & $4(3-7) n=2856$ & $<0.001$ \\
\hline
\end{tabular}

entire cohort: age $\geq 75$ years with adjusted OR $2.11(95 \%$ CI 1.45 to $3.07 \mathrm{p}<0.001)$ and Killip class $>1$ with adjusted OR 12.49 (95\% CI 8.64 to $18.05 \mathrm{p}<0.001)$.

\section{For patients $\geq 75$ years old by reperfusion strategy}

When we analysed the elderly group by reperfusion strategy; significant differences were demonstrated in age, Killip Class $>1$ and diabetes with increased cardiovascular comorbidities in the no reperfusion therapy group (table 3 ).

The unadjusted in-hospital outcomes in the elderly by reperfusion strategy are shown in table 4 . In hospital death and CHF were increased in the no reperfusion therapy group while resuscitated cardiac arrest occurred more often with primary PCI. Major bleeding requiring transfusion was similar in the three groups although
Figure 1 Reperfusion strategies among patients with STEMI by age in Alberta, 2006-2011. The figure represents applied reperfusion strategy by age groups $(<50,50-60,60-70$, $70-80$ and $\geq 80$ ) separated into: medical therapy without reperfusion (black $\triangle$ ), fibrinolysis (yellow $\downarrow$ ) and primary percutaneous coronary intervention $\mathrm{PCl}($ red $\square$ ).

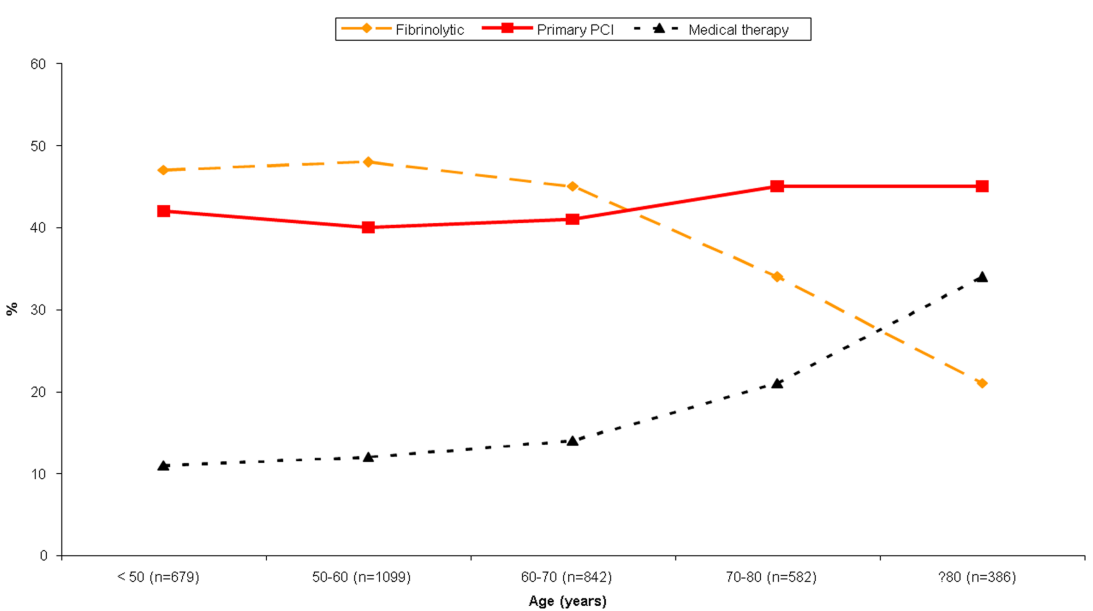


Table 2 In-hospital outcomes among patients with STEMI by age in Alberta, 2006-2011

\begin{tabular}{|c|c|c|c|}
\hline & $\begin{array}{l}\text { Age } \geq 75 \text { years } \\
(\mathrm{N}=646)\end{array}$ & $\begin{array}{l}\text { Age }<75 \text { years } \\
(\mathrm{N}=2942)\end{array}$ & p Value \\
\hline $\begin{array}{l}\text { Composite of Re-MI, death, cardiogenic shock } \\
\text { and congestive heart failure (\%) }\end{array}$ & $178(27.6)$ & 397 (13.5) & $<0.001$ \\
\hline Re-MI & $9(1.4)$ & $14(0.5)$ & 0.014 \\
\hline Death & $92(14.2)$ & $111(3.8)$ & $<0.001$ \\
\hline Cardiogenic shock & 85 (13.2) & $265(9.0)$ & 0.001 \\
\hline Congestive heart failure & $74(11.5)$ & $149(5.1)$ & $<0.001$ \\
\hline Cardiac arrest & $86(13.3)$ & $320(10.9)$ & 0.077 \\
\hline Major bleed (no transfusion) & $17(2.6)$ & $64(2.2)$ & 0.480 \\
\hline Major bleed (with transfusion) & $69(10.7)$ & $133(4.5)$ & $<0.001$ \\
\hline Non-major bleed & $14(2.2)$ & $51(1.7)$ & 0.454 \\
\hline \multicolumn{4}{|l|}{ Cerebrovascular event } \\
\hline Hemorrhage & $4(0.6)$ & $13(0.4)$ & 0.528 \\
\hline Ischaemic & $8(1.2)$ & $7(0.2)$ & 0.002 \\
\hline
\end{tabular}

Data are presented as $n(\%)$.

Re-MI, recurrent myocardial infarction.

major bleeding without transfusion was increased with fibrinolysis. The rate of stroke was not significantly different among the three groups. The rates of haemorrhagic stroke were $0 \%$ in the no reperfusion therapy versus $0.3 \%$ in the PPCI and $1.9 \%$ in the Fibrinolytic therapy ( $\mathrm{p}=0.083)$.

Across all three strategies in the elderly group there was high utilisation of invasive procedures during the index hospitalisation. In those receiving no reperfusion therapy $89(46.1 \%)$ underwent angiography, $52(27 \%)$ had non-urgent PCI $>24 \mathrm{~h}$ of presentation and $6(3 \%)$ had CABG. In those receiving fibrinolysis $134(84 \%)$ had an angiogram, 32 (20\%) had rescue PCI, 20
(12.5\%) had urgent PCI $<24 \mathrm{~h}$ of presentation, 55 (34\%) had non-urgent PCI $>24 \mathrm{~h}$ of presentation and 5 (3\%) had CABG. In those undergoing primary PCI 115 (5\%) had and additional non-urgent PCI and 7 (2.4\%) had CABG.

In a logistic regression analysis after adjusting for the same baseline characteristics as previously described the only predictor of the composite outcome for the elderly cohort was Killip class $>1$ with adjusted OR 7.37 (95\% CI 3.64 to 16.94$)$. For PPCI versus no reperfusion therapy the adjusted OR was 1.05 (95\% CIs 0.48 to 2.29) and for fibrinolysis versus no reperfusion therapy the adjusted OR was 0.57 (95\% CIs 0.21 to 1.53 ).

Table 3 Baseline characteristics of patients with STEMI aged $\geq 75$ years in Alberta, 2006-2011

\begin{tabular}{|c|c|c|c|c|}
\hline & $\begin{array}{l}\text { No reperfusion } \\
(n=193)\end{array}$ & $\begin{array}{l}\text { Primary PCI } \\
(n=293)\end{array}$ & $\begin{array}{l}\text { Fibrinolysis } \\
(n=160)\end{array}$ & p Value \\
\hline Age (year), median (IQR) & $83(79-87)$ & $80(78-84)$ & $81(78-86)$ & $<0.001$ \\
\hline Female & $98(50.8)$ & $140(47.8)$ & $65(40.6)$ & 0.151 \\
\hline BMI $\left(\mathrm{kg} / \mathrm{m}^{2}\right)$, median (IQR) & $26.6(23.2-30.5)$ & $25.9(23.0-28.8)$ & $26.6(24.0-30.7)$ & 0.028 \\
\hline SBP (mm Hg), mean (SD) & $136(35)$ & $139(34)$ & $134(30)$ & 0.371 \\
\hline Killip class $>1$ & $33(35.5)$ & $28(18.7)$ & $12(15.8)$ & 0.002 \\
\hline Prior angina & $66(34.2)$ & 79 (27.0) & $37(23.1)$ & 0.058 \\
\hline Previous MI & $55(28.5)$ & $60(20.5)$ & $32(20.0)$ & 0.075 \\
\hline Prior coronary revascularisation & 23 (11.9) & 39 (13.3) & $18(11.2)$ & 0.794 \\
\hline Hypercholesterolaemia & $73(37.8)$ & $126(43.0)$ & $65(40.6)$ & 0.523 \\
\hline Hypertension & $128(66.3)$ & $200(68.3)$ & $109(68.1)$ & 0.895 \\
\hline Diabetes & 52 (26.9) & 58 (19.8) & $16(10.0)$ & $<0.001$ \\
\hline Early CAD & $19(9.8)$ & $28(9.6)$ & $14(8.8)$ & 0.937 \\
\hline Chronic treatment with Aspirin & $60(31.1)$ & $73(24.9)$ & $45(28.1)$ & 0.324 \\
\hline Previous heart failure & $4(2.1)$ & $5(1.7)$ & $6(3.8)$ & 0.394 \\
\hline Atrial fibrillation & $4(2.1)$ & $6(2.0)$ & $4(2.5)$ & 0.941 \\
\hline $\begin{array}{l}\text { Symptom onset to FMC (min), } \\
\text { median (IQR) }\end{array}$ & $115(47-458)$ & $92(39-266)$ & $85(39-184)$ & 0.127 \\
\hline
\end{tabular}


Table 4 Outcomes among patients with STEMI aged $\geq 75$ years by treatments in Alberta, 2006-2011

\begin{tabular}{|c|c|c|c|c|}
\hline & $\begin{array}{l}\text { No reperfusion } \\
(n=193)\end{array}$ & $\begin{array}{l}\text { Primary } \mathrm{PCl} \\
(\mathrm{n}=293)\end{array}$ & $\begin{array}{l}\text { Fibrinolysis } \\
(n=160)\end{array}$ & p Value \\
\hline $\begin{array}{l}\text { Composite of Re-MI, death, cardiogenic shock } \\
\text { and CHF }\end{array}$ & $64(33.2)$ & $82(28.0)$ & $32(20.0)$ & 0.022 \\
\hline Re-MI & $1(0.5)$ & $5(1.7)$ & $3(1.9)$ & 0.470 \\
\hline Death & $38(19.7)$ & 39 (13.3) & $15(9.4)$ & 0.018 \\
\hline Cardiogenic shock & $21(10.9)$ & $43(14.7)$ & $21(13.1)$ & 0.480 \\
\hline Congestive heart failure & $28(14.5)$ & $38(13.0)$ & $8(5.0)$ & 0.011 \\
\hline Cardiac arrest & $16(8.3)$ & 49 (16.7) & $21(13.1)$ & 0.028 \\
\hline Major bleed (no transfusion) & $1(0.5)$ & $8(2.7)$ & $8(5.0)$ & 0.026 \\
\hline Major bleed (with transfusion) & $25(13.0)$ & $29(9.9)$ & $15(9.4)$ & 0.468 \\
\hline Non-major bleed & $6(3.1)$ & $5(1.7)$ & $3(1.9)$ & 0.540 \\
\hline \multicolumn{5}{|l|}{ Cerebrovascular event } \\
\hline Hemorrhage & 0 & $1(0.3)$ & $3(1.9)$ & 0.083 \\
\hline Ischaemic & $2(1.0)$ & $4(1.4)$ & $2(1.2)$ & 1.000 \\
\hline
\end{tabular}

Data are presented as $n(\%)$.

$\mathrm{CHF}$, congestive heart failure; $\mathrm{PCl}$, percutaneous coronary intervention; Re-MI, recurrent myocardial infarction.

\section{DISCUSSION}

Our finding from this observational cohort with real life physician practices, demonstrate that elderly patients with STEMI have more comorbidities and $30 \%$ of them received no reperfusion therapy compared to $13 \%$ of the younger patients. Elderly patients had worst outcomes with a doubling of composite in-hospital events. Additionally, a gradient was demonstrated for the composite event rate and mortality by choice of reperfusion strategy. For those receiving no reperfusion therapy the composite event occurred in $33 \%$ in the elderly compared to $17 \%$ of the younger. With PPCI and fibrinolysis it was $28 \%$ and $20 \%$ in the elderly and $16 \%$ and $10 \%$ in the younger, respectively. This was similarly shown when observing in-hospital death rates in the elderly with: no reperfusion therapy $20 \%$, PPCI $13 \%$ and fibrinolytic $9 \%$ and in the younger patients no reperfusion therapy $6.5 \%$, PPCI $4.6 \%$ and fibrinolytic $2.2 \%$.

These findings suggest that fibrinolytic therapy if used carefully in selected elderly patients may be beneficial and lead to reduced morbidity and mortality. These rates are different from previously published registry data analysis by Thiemann et $a l^{8}$ who found that the 30-day crude mortality rates in elderly who received fibrinolytic were $18 \%$ compared to $15.4 \%$ for no reperfusion therapy. In our cohort the death rates are lower overall except for the elderly group who received no reperfusion therapy. One could speculate that these elderly patients who were assigned to no reperfusion therapy most likely had contraindications to reperfusion strategy based on physicians assessment or declined such therapies. Additionally, it must be acknowledged that the VHR system of care incorporates a dual reperfusion strategy which allows the treating clinician to individualise by specific patient characteristics. Although elderly patients with STEMI have substantial increased risk compared to younger cohorts, as described in others work the application of reperfusion and evidence-based therapy has been associated with improved outcomes over the past decade..$^{910}$

In the past there have been concerns about using reperfusion strategies in elderly patients due to the risk of bleeding, haemorrhagic CVA and contraindications to both fibrinolysis and PCI. ${ }^{8}{ }^{11}$ The bleeding rates in our inclusive study were higher in the elderly with major bleeding occurring in $13 \%$ vs $7 \%$ in the younger patients with STEMI. The approximate doubling of bleeding in the elderly cohort is similar to other contemporary analyses although direct comparison is challenging since others limited analysis to primary PCI (transradial primary PCI in $\geq 75$ years: severe bleeding $6.5 \%$ and need for transfusion $9.9 \%)^{12}$ and secondary analysis of clinical trials of primary PCI. ${ }^{13}$ The rates of haemorrhagic stroke in the entire cohort were low and were not significantly different between the elderly and the younger patients $(4(0.6 \%)$ vs $13(0.4 \%) \mathrm{p}=0.52)$. Although ischaemic stroke occurred more frequently in the elderly ( $8(1.2 \%)$ vs $7(0.2 \%), p=0.002)$.

Specific to the elderly population, major bleeding requiring transfusion was similar in the three reperfusion groups, although major bleeding without transfusion was increased with fibrinolysis. Furthermore the rates of haemorrhagic stroke in the elderly were not significantly different among the three reperfusion groups, although numerically higher with fibrinolysis occurring in three patients. These safety results may be even improved further with incorporation of the half dose fibrinolytic strategy in patients $>75$ years as studied in the Strategic Reperfusion Early After Myocardial infarction study (STREAM). ${ }^{14}$

Finally when looking at contemporary practices it is apparent that even in those patients that did not receive acute reperfusion there was a high utilisation of invasive investigation and revascularisation. In the younger cohort $72 \%$ of the no reperfusion therapy patients had subsequent angiograms, $44 \%$ of them underwent non- 
urgent PCI after $24 \mathrm{~h}$ of the presentation and $6 \%$ were referred to CABG, which may have played a role in the overall good outcomes in this group. Similarly in the patient's $\geq 75$-year-old group, $46 \%$ of the no reperfusion therapy patients had subsequent angiograms, $27 \%$ of them underwent non-urgent PCI after $24 \mathrm{~h}$ of the presentation and 3\% were referred to CABG. Previously we have assessed the reason and rational for patients with STEMI to not receive acute reperfusion from a subset of this cohort. The major reasons were: late presentation (approximately $40 \%$ of untreated), patient or family request for conservative care (approximately 23\% of untreated), and planned primary PCI without an identifiable culprit lesion or failed attempted PCI (approximately $20 \%$ of untreated). ${ }^{15}$

Internationally there has been a dedicated attempt to apply mechanical reperfusion as the strategy of choice for all patients with STEMI with this being emphasised especially in the elderly patients due to their increased risk of bleeding complications from fibrinolysis. This real world contemporary analysis based on a regional reperfusion programme which has incorporated a dual reperfusion strategy with individual patient selection demonstrates excellent clinical outcomes in elderly patients with STEMI receiving fibrinolysis.

\section{Limitations}

This study is based on a comprehensive inclusive registry and is a reflection of a real life cohort and actual practices of clinicians. The observational nature of the study makes it prone to information bias. The registry is part of a dedicated quality assurance programme and only tracks patients outcomes while in hospital. Our analyses maybe limited by the sample size especially relevant to the elderly group. The registry data lacks non-cardiovascular comorbidities that may influence clinician's reperfusion decisions. The complexity of the decision making process in the treatment of acute myocardial infarction may have multiple confounders unaccounted for. Alberta is a large province with large rural catchment area where reperfusion strategy by PCI may require hours in transfer and Fibrinolytic may be chosen over PCI due to the time factor to preserve myocardium. ${ }^{11}$

\section{CONCLUSIONS}

Elderly patients have more comorbidities, worst in-hospital clinical outcomes and are more likely to receive no reperfusion therapy for STEMI compared to patients $<75$ years. When reperfusion is undertaken practising clinicians preferred primary PCI over fibrinolysis in both age groups. Acknowledging physician driven patient selection, outcomes appear favourable in the elderly receiving fibrinolysis. Further systematic assessment of elderly patients with STEMI is warranted.
Competing interests None declared.

Ethics approval University of Alberta HREB.

Provenance and peer review Not commissioned; externally peer reviewed.

Open Access This is an Open Access article distributed in accordance with the Creative Commons Attribution Non Commercial (CC BY-NC 4.0) license, which permits others to distribute, remix, adapt, build upon this work noncommercially, and license their derivative works on different terms, provided the original work is properly cited and the use is non-commercial. See: http:// creativecommons.org/licenses/by-nc/4.0/

\section{REFERENCES}

1. Mehta RH, Rathore SS, Radford MJ, et al. Acute myocardial infarction in the elderly: differences by age. J Am Coll Cardiol 2001;38:736-41.

2. Alexander KP, Newby LK, Armstrong PW, et al. Acute coronary care in the elderly, part II: ST-segment-elevation myocardial infarction: a scientific statement for healthcare professionals from the American Heart Association Council on Clinical Cardiology: in collaboration with the Society of Geriatric Cardiology. Circulation 2007;115:2570-89.

3. Boucher JM, Racine N, Thanh TH, et al, Quebec Acute Coronary Care Working Group. Age-related differences in in-hospital mortality and the use of thrombolytic therapy for acute myocardial infarction. CMAJ 2001;164:1285-90.

4. Hafiz AM, Jan MF, Mori N, et al. Contemporary clinical outcomes of primary percutaneous coronary intervention in elderly versus younger patients presenting with acute ST-segment elevation myocardial infarction. J Interv Cardiol 2011;24:357-65.

5. [No authors listed]. Indications for fibrinolytic therapy in suspected acute myocardial infarction: collaborative overview of early mortality and major morbidity results from all randomised trials of more than 1000 patients. Fibrinolytic Therapy Trialists' (FTT) Collaborative Group. Lancet 1994;343:311-22.

6. Berger AK, Schulman KA, Gersh BJ, et al. Primary coronary angioplasty vs thrombolysis for the management of acute myocardia infarction in elderly patients. JAMA 1999;282:341-8.

7. Berger AK, Radford MJ, Wang Y, et al. Thrombolytic therapy in older patients. J Am Coll Cardiol 2000;36:366-74.

8. Thiemann DR, Coresh J, Schulman SP, et al. Lack of benefit for intravenous thrombolysis in patients with myocardial infarction who are older than 75 years. Circulation 2000;101:2239-46.

9. Velders MA, James SK, Libungan B, et al. Prognosis of elderly patients with ST-elevation myocardial infarction treated with primary percutaneous coronary intervention in 2001 to 2011: a report from the Swedish Coronary Angiography and Angioplasty Registry (SCAAR) registry. Am Heart J 2014;167:666-73.

10. Viana-Tejedor A, Loughlin G, Fernandez-Aviles F, et al. Temporal trends in the use of reperfusion therapy and outcomes in elderly patients with first ST elevation myocardial infarction. Eur Heart $J$ Acute Cardiovasc Care. Published Online First: 5 Jan 2015. doi:10.1177/2048872614565928

11. Shavadia J, Ibrahim Q, Sookram S, et al. Bridging the gap for nonmetropolitan STEMI patients through implementation of a pharmacoinvasive reperfusion strategy. Can J Cardiol 2013;29:951-9.

12. Rodriguez-Leor O, Fernandez-Nofrerias E, Carrillo X, et al. Results of primary percutaneous coronary intervention in patients $\geq 75$ years treated by the transradial approach. Am J Cardiol 2014;113:452-6.

13. Ielasi A, Brugaletta S, Silvestro A, et al. Everolimus-eluting stent versus bare-metal stent in elderly ( $\geq 75$ years) versus non-elderly ( $<75$ years) patients with ST-elevation myocardial infarction undergoing primary percutaneous coronary intervention: insights from the examination trial. Int J Cardiol 2015;179:73-8.

14. Armstrong PW, Gershlick A, Goldstein P, et al. The Strategic Reperfusion Early After Myocardial Infarction (STREAM) study. Am Heart J 2010;160:30-5.

15. Deckert-Sookram J, Sookram S, Valaire S, et al. Evaluating clinical reason and rationale for not treating STEMI patients with reperfusion therapy: InSight from a comprehensive cohort therapy. Can J Cardiol 2009;25(Suppl B):133B-4B. 